\title{
Uma experiência de projeto de letramento crítico com literatura negra feminina
}

\author{
Viviane Cristina Vieira ${ }^{1}$ \\ Rayanne Oliveira Fontenele Vasconcelos ${ }^{2}$
}

\begin{abstract}
Resumo: Nesta pesquisa apresento as percepções iniciais do projeto "Mulheres Inspiradoras". O objetivo é analisar representações de estudantes no ambiente escolar e reprodução de preconceitos sociais. Com base na Análise de Discurso Crítica (FAIRCLOUGH, 2003) e nos modos de operação da ideologia (THOMPSON, 1995), investigamos o discurso de preconceito racial e de gênero no contexto escolar. A pesquisa foi desenvolvida em uma escola pública de em Sobradinho - DF, com estudantes do sétimo ano. Os resultados revelam que desde cedo já se constrói a imagem do jovem negro como uma ameaça social e um corpo que o Estado pode violar.
\end{abstract}

Palavras-chave: racismo, gênero, Mulheres Inspiradoras, educação.

\section{A critical literacy project experience with black female literature}

\begin{abstract}
In this research I present the initial perceptions of the project "Inspiring Women". The objective is to analyze the students' representations in the school environment and the reproduction of social prejudices. Based on the Critical Discourse Analysis (FAIRCLOUGH, 2003 ) and the modes of operation of ideology (THOMPSON, 1995) we investigated the discourse of racial prejudice and gender in the school context. The research was developed in a public Elementary school, in Sobradinho - DF, with students of the seventh year. The results reveal that from an early age the image of the young black man is already built as a social threat and a body that the state can violate.
\end{abstract}

Keywords: racism, gender, Inspiring Women education.

\section{INTRODUÇÃO}

\footnotetext{
1 Professora Associada da Universidade de Brasília/Depto. de Linguística, Português e Línguas Clássicas/Programa de Pós-Graduação em Linguística. Doutora e Mestra em Linguística/Linguagem e Sociedade pela Universidade de Brasília. Editora do periódico Cadernos de Linguagem e Sociedade (Conceito Capes A2). Também é Vice-Coordenadora do Núcleo de Estudos de Linguagem e Sociedade (NELiS-UnB) e do Grupo de pesquisa Laboratório de Estudos Críticos do Discurso (LabEC-UnB/CNPq). Desenvolve atividades de ensino, pesquisa e extensão com o projeto Estudos Críticos do Discurso nas práticas de aprendizagem de Português como língua materna. vivi@unb.br
}

${ }^{2}$ Licenciada em Letras-Português pela Universidade de Brasília. Professora da Secretaria de Educação do Distrito Federal. Membra do Núcleo de Estudos de Linguagem e Sociedade (NELiS - UnB). Pesquisadora de Iniciação Científica. rayannefontenele21@gmail.com 


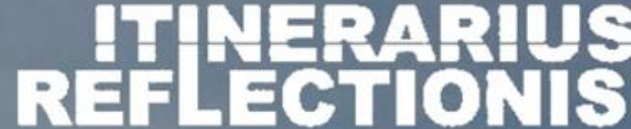

Revista Eletrônica de Graduaçāo e Pós-Graduaçäo em Educaçāo

O objetivo deste artigo é apresentar uma experiência inicial de pesquisa-ação colaborativa no âmbito das atividades do projeto Laboratório de Estudos Críticos do Discurso: reflexões sobre ensino de português como língua materna, cujo foco é investigar e problematizar práticas sociais de ensinoaprendizagem de português como língua materna, observando processos situados de ação/interação, de identificação e de representação discursiva, parcialmente (con)formadores de valores, crenças, normas, atitudes, relações sociais, subjetividades, poderes e saberes. Foi realizado um estudo qualitativo, por meio de pesquisa ação em uma escola localizada em Sobradinho-DF, para investigar aspectos sociodiscursivos (pedagógicos, identitários, interacionais, representacionais, relacionais) da implementação e dos resultados do Projeto Pedagógico "Mulheres Inspiradoras", desenvolvido em escolas públicas da SEDF com o objetivo de incentivar práticas de educação para a cidadania, para a equidade de gênero, combate ao racismo e para a transformação social.

A pesquisa origina-se de percepções construídas durante realização de trabalho de conclusão de curso que teve como tema norteador a legitimação de práticas machistas por meio do discurso. Entendendo que não só ações. Atitudes, mas também o discurso naturaliza violências físicas, é primordial desconstruir desde cedo nossas práticas opressoras. Como agentes sociais começamos a questionar o mundo desde muito pequenos, mas somente quando atingimos certa idade, no convívio em sociedade, começamos a reproduzir e engessar as opressões. É por acreditar que a educação é transformadora que se faz necessário trabalharmos com projetos pedagógicos de cunho social, incentivando a reflexão sobre as práticas sociais estabelecidas.

É a partir do recorte de gênero, classe e raça que nasce no DF o projeto Mulheres Inspiradoras. Não há dúvidas hoje sobre a necessidade de retomar e contar a nossa história pela nossa perspectiva negra, latino-americana, feminina etc. sem a interferência do olhar eurocentrado; de aproximar a narrativa da nossa realidade e fazer da educação uma educação libertadora e de representatividade (FREIRE, 1975). Nasce, então, como resultado desse movimento, a ideia de transformar a imagem construída para as mulheres.

Gina, idealizadora do projeto, é uma professora da rede pública que estava passando por uma crise profissional e não conseguia fazer os alunos se envolverem e se engajarem com as propostas, como ela narra (ALBUQUERQUE E DIAS, 2018). Apesar de estar passando por um processo de adoecimento, foi na educação que ela criou forças 


\section{MTIFAR REFLECTIONIS}

Revista Eletrônica de Graduação e Pós-Graduaçäo em Educaçāo

e começou o projeto, logo após de se deparar com o vídeo de uma aluna de 13 anos que se exibia de forma sensual em uma rede social, a aluna pareceu não se incomodar com os comentários machistas na plataforma. Entretanto, isso incomodou a professora de tal forma, que a fez pensar em um projeto que desconstruísse desde cedo como a mulher é vista socialmente. O projeto seguiu então o propósito de desenvolver práticas de letramento crítico que problematizassem a representação das mulheres como "objeto sexual"; de (re)pensar a respeito do papel da mulher na sociedade e a sua representação, relacionando a realidade dos estudantes e o debate sobre igualdade de gênero, relações de gênero e machismo.

O projeto acontece hoje no DF e conta com a participação de mais de 30 escolas por edital. Ao longo do projeto estudantes realizam a leitura de seis obras de autoria feminina; fazem o estudo da biografia de dez grandes mulheres e produzem um texto autoral, em primeira pessoa, sobre a história de uma mulher do seu círculo social, que consideram a mais inspiradora de todas. Normalmente, as "mulheres inspiradoras", para os/as estudantes participantes do projeto, são familiares.

Dentre tantos textos, é possível trabalhar o que o currículo orienta (gêneros textuais, períodos simples e composto, pontuação, escolas literárias etc.) e ir além, promovendo práticas de leitura (multimodal, crítica), de escrita, escuta, oralidade, de reflexão linguística (PCN/BRASIL, 1997). Além disso, é importante levar estudantes a refletir sobre suas práticas sociais, nas quais se inserem o machismo e o racismo. $\mathrm{O}$ projeto busca avançar sobre o debate de um machismo que afeta não somente as mulheres e aponta para a construção de masculinidades sadias. Aponta também para a construção da identidade de autora/a, pela valorização cultural, comunitária, familiar por meio da auto-representação em histórias e narrativas.

Sabe-se que as mulheres sempre foram apagadas pela história, desde as mulheres que estiveram nos mais altos postos até as grandes heroínas presentes no dia-a-dia, pois a história e as supostas "verdades" são escritas por homens brancos de uma elite restrita segundo uma lógica racional-legal que sustenta práticas de exploração capitalista. Não foi diferente na literatura latino-americana. Proporcionalmente, é bem menor o número de autoras mulheres lidas em escolas, menor ainda o de mulheres negras, que historicamente são silenciadas e têm sua narrativa roubada e re-contada (quando contada) 


\section{ITHepapius REFLETIONIS}

Revista Eletrônica de Graduaçāo e Pós-Graduaçāo em Educaçāo

por outras pessoas, o que é facilmente verificável nas obras indicadas para processos seletivos, cujas listas, não raro, não indicam sequer uma autora mulher.

Um exemplo prático de como homens brancos vêm ocupando o lugar de mulheres negras é o caso recente de Conceição Evaristo, que no ano de 2018 entregou sua autocandidatura para Associação Brasileira de Letras - ABL - e, apesar de todo o apoio nacional, teve o seu lugar ocupado pelo cineasta Cacá Diegues, reforçando o estereótipo de quem constrói e ocupa lugares importantes na nossa história.

\section{DISCURSO E IGUALDADE DE GÊNERO-RAÇA-CLASSE}

$\mathrm{Na}$ perspectiva teórico-metodológica da análise de discurso crítica, que fundamenta o projeto, a linguagem é entendida como uma prática social (discurso), ou seja, um aspecto das práticas sociais que se constitui e é constituído, dialeticamente, com outros os demais aspectos que compõem a vida social: relações sociais, mundo material e pessoas (com suas crenças, valores, histórias). Isso implica que práticas sociais são constituídas simultaneamente por todos esses aspectos, de modo que questões sociais são, em parte, questões de discurso, e vice-versa (CHOULIARAKI \& FAIRCLOUGH, 1999).

Apresentamos, assim, a proposta teórico-metodológica e ontológica básica que baliza nossas pesquisas sobre educação e gênero-sexualidade desenvolvidas atualmente no Programa de Pós-Graduação em Linguística e no Núcleo de Estudos de Linguagem e Sociedade da Universidade de Brasília. Com a participação recente no Projeto políticopedagógico Mulheres Inspiradoras, idealizado e coordenado em escolas públicas do DF pela professora da Secretaria de Educação do Distrito Federal e mestranda do Programa Gina Vieira Ponte de Albuquerque, surgiram novas demandas de estudo/pesquisa.

O Projeto pedagógico didático Mulheres Inspiradoras foi realizado, inicialmente, por Albuquerque (2015) em uma escola apenas, o Centro de Ensino Fundamental 12 da cidade satélite de Ceilândia, Distrito Federal (DF), em 2014, com estudantes de $9^{\circ}$ ano. O projeto (que é, mais apropriadamente, político-pedagógico e não só pedagógico) busca promover, nas escolas públicas atendidas, práticas de letramento (leitura-escrita) mais críticas sobre relações de gênero, com foco na valorização das mulheres; na luta contra violências e privação de direitos das mulheres; no protagonismo estudantil e no desenvolvimento de práticas de leitura e escrita mais autorais. As ações norteadoras do 


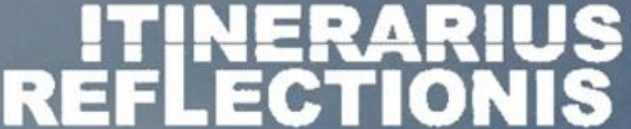

Revista Eletrônica de Graduaçāo e Pós-Graduaçäo em Educaçāo

projeto, que recebeu cinco prêmios de educação e direitos humanos, incluem estudo de biografias de mulheres do mundo, do Brasil e das comunidades; leitura de obras de autoria feminina negra, como Não vou mais lavar os pratos e Só por hoje vou deixar meu cabelo em paz, de Cristiane Sobral (SOBRAL, 2010, 2014), e Quarto de Despejo: diário de uma favelada, de Carolina Maria de Jesus (JESUS, 2007), e a produção autoral de biografias das "mulheres inspiradoras" das comunidades do DF. No ano de 2017, o Projeto foi aderido por mais 15 escolas da rede pública do DF por meio do Programa de Ampliação da Área de Abrangência do Projeto Mulheres Inspiradoras, com previsão de adesão de novas escolas em 2018.

Com base na análise de discurso crítica, nossa prática-teórica assenta-se na compreensão da linguagem como um momento irredutível da vida social, que se relaciona dialeticamente com os outros momentos (relações sociais, mundo material e pessoas, com suas crenças, valores, histórias) e, por isso, tem efeito sobre eles assim como se constitui desses demais momentos, conforme teorização de Chouliaraki e Fairclough (1999) e Fairclough (2003) no contexto europeu que viabilizou a chegada no Brasil da transdisciplina análise de discurso crítica (SUPRIMIDO).

Possibilitando e constrangendo nossas maneiras de agir e interagir, de representar e de identificar(se) na vida social, ou seja, nas dinâmicas do poder, do saber e do ser para a Teoria decolonial, nesta compreensão a linguagem (ou seja, o discurso como momento de práticas sociais) constitui-se socialmente e constitui o social, sendo, assim, parcialmente constitutiva das ações e relações sociais, das (auto)identidades, dos sistemas de normas, valores, conhecimento e crença e do mundo material.

Com esse aporte, buscamos em nossas pesquisas tecer a crítica social situada de práticas sociais envolvidas em processos de ensinoaprendizagem de português como língua materna e suas implicações naquilo que nos (con)forma como agentes de ações/interações, de conhecimento e de ação moral (MOREY, 1995) em práticas escolares de produção e circulação de conhecimento, que podem contribuir para manter mas também para problematizar relações de opressão (Freire, 2005[1970]).

Assim, retomando (SUPRIMIDO), com base na análise de discurso crítica, o Discurso (se)constitui dialeticamente (n)as práticas sociais, nos principais modos relativamente estáveis como 


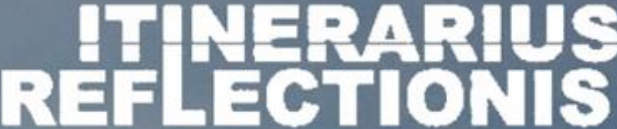

Revista Eletrônica de Graduaçāo e Pós-Graduaçäo em Educaçāo

- agimos e interagimos no mundo (em gêneros discursivos, nas relações de poder que nos constituem como agentes atuando com pessoas e sobre elas);

- representamos e projetamos o mundo (em discursos particulares, em relação às representações que nos constituem como agentes de conhecimento) e

- nos identificamos e identificamos a outrem (em estilos, nas relações éticas que constituem nossos agenciamentos como seres de ação moral).

Tudo isso, em redes de discurso socialmente organizadas, “ordenadas". Isto é, tais modos como o discurso figura nas práticas sociais são organizados em cada campo social (pedagógico, científico, interpessoal, político, econômico), formando, então, a sua ordem do discurso, ou seja, a sua faceta discursiva, isso sempre em relação com redes de outros campos sociais e suas respectivas redes de ordens do discurso (CHOULIARAKI \& FAIRCLOUGH, 1999, p. 114).

Nossa parcela inicial de contribuição para a teorização decolonial, que vem sendo desenvolvida desde o final de 1990 na América Latina em diversas universidades, é colocar a Linguística como parte das disciplinas a serem decolonizadas assim como como também é nosso papel contribuir para a crítica dos modos como a linguagem é usada para a criação e manutenção de ideologias (ou seja, de sentidos a serviço da opressão) associadas ao "mito do eurocentrismo" (incluindo o "mito da modernidade", conforme DUSSEL, 2015) nas relações de poder, nas ciências, nos saberes, nos modos de ser, e os problemas sociais a ele atrelados. Nosso empenho é contribuir para a crítica e para a decolonização das formas hegemônicas eurocentradas de poder, de ser, de viver, de pensar, de se relacionar, de fazer ciência que têm predominado no Brasil (nosso lugar de trabalho), considerando-se que tal crítica enfoca a faceta discursiva dos processos de (de)colonialidade do poder, do saber e do ser.

Várias ideologias (que são representações, portanto discursos particulares a serviço de opressões) estão atreladas ao "mito do eurocentrismo/etnocentrismo" e precisam, defendemos, ser investigadas em busca da crítica e da conscientização (ou, mais apropriado, da de-colonização) de crenças, valores, normas, discursos, comportamentos que sustentam a colonialidade do poder, do saber e do ser nas práticas sociais e vivências no sistema-mundo moderno/colonial, tal como teorizado nas Ciências Sociais (BALLESTRIN, 2013). Nos termos de Grosfoguel (2008, p. 113), um "sistema mundo 


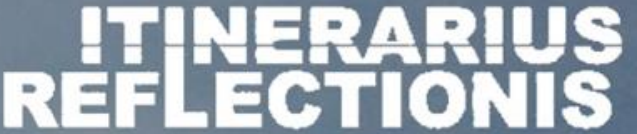

Revista Eletrônica de Graduaçāo e Pós-Graduaçäo em Educaçāo

europeu/euro-norte-americano moderno/capitalista/colonial/patriarcal", sustentado também por ideologias ligadas a relações de gênero-sexualidade.

Dentro do recente campo diversificado da crítica decolonial nos estudos críticos do discurso, vertemos esforços para re-pensar abordagens teóricas, ontológicas, metodológicas e políticas coerentes para nossos estudos sobre problemáticas sociais de gênero-sexualidade. Assim sendo, entendemos ser passível de a crítica impactar sobre nossas práticas sociais e simbólicas mostrando o poder constitutivo do discurso para manter o mito do eurocentrismo/etnocentrismo, e os problemas sociais a ele associados, mas também seu poder para decolonizar práticas sociais e crenças que nos oprimem, numa postura engajada com questões relacionadas a poder e justiça na vida social (FAIRCLOUGH, 2003).

Como observa Quijano (2000, p. 223), certos dualismos têm legitimado e sustentado a colonialidade do saber, a colonialidade do poder e a colonialidade do ser no sistema mundo colonial-moderno. Dualismos de valor hierarquicamente organizados mantêm as lógicas de dominação e exploração patriarcal colonial-imperialista: humano/não-humano, homem/mulher, branco/negro, branco/indígena, cultura/natureza, espírito/corpo, humano/natureza, masculino/feminino, razão/emoção, dentre outros.

Conforme Torres $(2007 \text {, p. 130-1) })^{3}$, colonialidade refere-se "à forma como o trabalho, o conhecimento, a autoridade e as relações inter-subjetivas se articulam através do mercado capitalista mundial e da ideia de raça, sobre três bases principais":

- a colonialidade do poder, que se refere à "inter-relação entre formas modernas de exploração e dominação";

- a colonialidade do saber, referente ao "papel da epistemologia e as tarefas gerais da produção de conhecimento e a reprodução de regimes de pensamento coloniais", e a

- a colonialidade do ser, que se refere ao processo de "colonização cognitiva", "da experiência vivida da colonização e seu impacto na linguagem".

É dessa forma que várias outras ideologias (o que nas ciências sociais é lido como "mitos"), além dessa do "corpo como objeto de dominação e exploração", são engendradas na sustentação da matriz colonial de poder, com suas normas, práticas,

\footnotetext{
${ }^{3}$ Os originais em língua estrangeira foram traduzidos pelas autoras.
} 


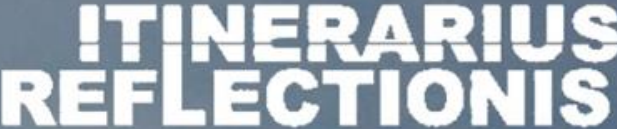

Revista Eletrônica de Graduaçāo e Pós-Graduaçāo em Educaçāo

técnicas, ações e relações, representações, identificações, em redes de ordens do discurso, nos termos da análise de discurso crítica.

$\mathrm{Na}$ perspectiva transformacional de sociedade com que trabalhamos, a estrutura social é condição e restrição para a inter-ação humana em práticas sociais, mas é, também, o resultado dessa inter-ação (SUPRIMIDO). Agência humana e estrutura social constituem-se, assim, transformacionalmente, nas práticas sociais que articulam Discurso, pessoas (com crenças, valores, normas, comportamentos) em relações sociais num mundo material específico, de modo relativamente estável e em tempos-espaços particulares. Isso implica, primeiro, que a identificação não se limita a construções discursivas, embora seja, parcialmente, um processo de construção de significado, "baseado em atributos culturais inter-relacionados que prevalecem sobre outras fontes de significado" (CASTELLS, 2001, p. 22).

Outro aspecto a se considerar é que a identificação pode ser parte constitutiva de estruturas opressoras, contribuindo para mantê-las, somente se forem internalizadas pelas pessoas, passando, desse modo, a constituir os significados da experiência vivida, o que pode ser problematizado em pesquisas etnográficas-colaborativas. Consideramos, então, tanto as possibilidades e os constrangimentos sociais que constituem as identificações, quanto os agenciamentos individuais reprodutores ou transformadores na construção de (auto)identidades, em processos de (de)colonização do ser.

Além das problemáticas sociodiscursivas ligadas à visão androcêntrica de mundo, segundo a qual o masculino ocuparia posição central nas relações e práticas sociais, configurando-se como gênero social dominante (SOUSA \& CARVALHO, 2003), nos interessam nas pesquisas as relações de gênero e suas expressões situadas no continuum entre masculino-feminino, frequentemente apagado discursivamente em estratégias ideológicas de silenciamento/invisibilização de outras possibilidades de representação não-binárias de gênero-sexo, a exemplo do que identificam Vieira e Gonzales (2019).

Moore (2000) problematiza que a identidade de gênero é construída e vivida por indivíduos, que podem assumir múltiplas posições de sujeito dentro de uma gama de discursos e práticas sociais, levando em conta principalmente a experiência subjetiva da identidade, o fato físico de ser um sujeito num corpo e a continuidade histórica do sujeito, em que posições passadas tendem a sobredeterminar posições presentes de sujeito. As questões de gênero, portanto, sendo socioculturalmente situadas e negociadas, mobilizam 


\section{MTIFAR REFLECTIONIS}

Revista Eletrônica de Graduação e Pós-Graduaçāo em Educaçāo

redes de poderes, práticas, agenciamentos, normas e saberes em lutas hegemônicas, parcialmente discursivas.

\section{UMA APROXIMAÇÃO INICIAL NO CENTRO EDUCACIONAL FUNDAMENTAL 03 DE SOBRADINHO}

Com tal referencial teórico-metodológico, a pesquisa de PROiC, aqui apresentada, foi realizada em uma das escolas contempladas pelo edital do projeto. Para a coleta de dados analisamos as falas de alunos e alunas em espaços mistos. $\mathrm{O}$ público alvo são alunos do ensino fundamental II, do $7^{\circ}$ ano do Centro Educacional Fundamental 03 de Sobradinho. Utilizamos como método a pesquisa-ação e a pesquisa colaborativa. A primeira, pois não iremos nos limitar apenas a uma forma de ação, o intuito é conscientizar e aumentar o nível de conhecimento das pessoas envolvidas na pesquisa, tanto de quem a escreve, quanto dos grupos inseridos nesta. A segunda, pois queremos levar até a escola a cultura de se pensar sobre a prática de suas ações, de propor soluções e refletir sobre as estruturas ali presente.

$\mathrm{Na}$ proposta de abordagem teórico-metodológica da ADC, de Chouliaraki e Fairclough (1999), o objetivo é refletir sobre a mudança social contemporânea, sobre mudanças globais de larga escala e sobre a possibilidade de práticas críticas sobre estruturas estabilizadas na vida social.

O contato inicial com a escola aconteceu na perspectiva de construir o projeto Mulheres Inspiradoras em conjunto com o professor de história, entretanto, antes mesmo de iniciar o trabalho fui convocada para trabalhar como professora no próprio centro de ensino em que o projeto acontece. Como membro da equipe pudemos observar e perceber a importância de uma escola que não apenas apresenta projetos aos professores, como faz do projeto o cotidiano da escola. No Centro de Ensino Fundamental 03 de Sobradinho (CEF 03) estão sendo desenvolvidos três projetos simultaneamente: Pela lente do amor, São João Mulheres Inspiradoras e a Gincana 2019.

O projeto Pela lente do amor acontece na perspectiva de trabalhar a afetividade, conhecer outras linguagens trabalhando e resgatando a própria voz dos alunos no ambiente escolar e ensinando a ter voz social, dentro desse mesmo projeto está inserido 


\section{ITIFPARINS REFLECTIONIS}

Revista Eletrônica de Graduaçāo e Pós-Graduaçāo em Educaçāo

o Projeto Mulheres Inspiradoras (PMI). Durante todo o ano os alunos aprendem a manusear os instrumentos de áudio e vídeo para fazer um trabalho final com as gravações das biografias das mulheres que os alunos identificam como inspiradoras. O PMI dentro do CEF 03 foi ressignificado de forma que contemplasse a realidade dos alunos e dos projetos que a escola já se propõe a desenvolver. De forma lúdica, os alunos trabalham a criatividade, realizando desde a escrita do roteiro até a produção do vídeo, e os alunos são avaliados nas mais diversas competências, o que tira o peso de apenas uma avaliação escrita e formal e valoriza as diversas formas de linguagens e comunicações.

O São João Mulheres Inspiradoras busca empoderar as várias Marias que existem na cidade, Marias que representam, pelo nome, todas as mulheres. Simultaneamente com os preparativos do São João da escola, acontece a Gincana, norteada também com a temática voltada para as mulheres. As equipes da gincana levam o nome de mulheres que foram importantes para a história, de escolha dos próprios professores conselheiros, todas os alunos devem saber qual foi a importância dessa mulher e porque ficou marcada na história.

É nessa perspectiva que é construído o ano letivo do CEF 03: uma equipe de professores que acreditam na educação como instrumento de transformação, abraçando e incentivando os outros colegas de trabalho a fazerem o mesmo, mudando a concepção de uma educação estruturalista, onde o professor seria o único agente dentro da escola e os alunos, apenas receptores.

A dinâmica da gincana é construída primeiro com a escolha do nome de uma mulher que está na história para ser representante de cada turma que somos conselheiros, o nome que escolhemos para representar o $7^{\circ}$ ano " $\mathrm{C}$ " e o $6^{\circ}$ ano " $\mathrm{C}$ " foi o da cantora Elza Soares. Com isso, levamos para a sala de aula a história de Elza Soares, onde pouquíssimos alunos conheciam a cantora e nenhum deles conheciam a trajetória de vida dela. Depois de lermos a biografia ${ }^{4}$ disponibilizada na internet, iniciamos uma discussão a respeito da vida de Elza, onde os comentários variaram entre "vida triste", "mulher forte" e que "a aparência dela era similar a de um travesti". Na tentativa de resgatar a importância de tratar dos temas que as músicas dela trazem, falamos sobre racismo, machismo e violência contra a mulher. Depois de trazer a história para sala de aula, como

${ }^{4}$ Disponível em: 〈https://pt.wikipedia.org/wiki/Elza_Soares> Acesso em 22 de julho de 2019. 


\section{ITImparins REFLECTIONIS}

Revista Eletrônica de Graduaçāo e Pós-Graduaçāo em Educaçāo

tarefa da gincana, fizemos um painel sobre a Elza, onde os alunos se envolveram ainda mais com a história, pesquisando imagens e selecionando os fatos mais marcantes para estarem presentes no painel.

Convidamos alguns/mas alunos/as para perguntar sobre os temas debatidos em sala. Foram feitas as seguintes perguntas:

"Por que vocês acham que sabiam quem era o Garrincha mas não sabiam quem era a Elza Soares?"

"Foi interessante para vocês saberem sobre a história dela? Por quê?"

"Vocês acham importante falar sobre os temas da música dela em sala de aula?"

Ambas as respostas são similares: os/as colaboradores/as acreditam que sabem quem é o Garrincha porque o futebol é um esporte muito conhecido no Brasil e todo mundo presta atenção. A aluna complementou dizendo que uma prova disso é a desvalorização do futebol feminino. A aluna respondeu ainda que é importante falar sobre a história dela em sala para ver que se a cantora conseguiu passar por tudo isso, ela também é capaz de superar as dificuldades da vida. Enquanto o terceiro aluno colaborador respondeu que acha importante falar apenas sobre violência contra a mulher, que acha inútil falar sobre machismo e racismo pois as pessoas não irão mudar sua forma de pensar.

Isso converge com nosso interesse de discutir, além das problemáticas sociodiscursivas ligadas à visão androcêntrica de mundo, segundo a qual o masculino ocuparia posição central nas relações e práticas sociais, configurando-se como gênero social dominante (SOUSA \& CARVALHO, 2003), nos interessam nas pesquisas as relações de gênero e suas expressões situadas no continuum entre masculino-feminino, frequentemente apagado discursivamente em estratégias ideológicas de silenciamento/invisibilização de outras possibilidades de representação não-binárias de gênero-sexo. Depois de conversar com esses três alunos separadamente, abordamos um pouco mais o tema "machismo". Foi assim que iniciamos uma conversa informal, de onde surgiram vários temas e as falas que serão discutidas aqui de acordo com o modus operandi da construção das identificações em sala de aula e da reprodução das ideologias dominantes, com base em Thompson (1995). 


\section{ITHepapius REFLECTIONIS}

Revista Eletrônica de Graduaçāo e Pós-Graduaçāo em Educaçāo

Das conversas emergiram dados que apontaram para um processo de nominalização/naturalização, em que sentenças, ou parte delas, descrições da ação e dos participantes nelas envolvidos são transformados em nomes que reificam discursos ideológicos de preconceitos raciais e de gênero. Apresentamos a seguir uma passagem (não identificada) de um diálogo da pesquisa:

Aluna: Não, mas tem homem, tipo o Andé ${ }^{5}$, ele usa o short no meio da bunda. Aluno: Mas aí é outro estilo de homem.

Aluna: Agora é modinha, de usar short abaixo do joelho. O short acima do joelho eles falam que é feio.

Professora: Mas o Fabrício é outro estilo de homem?

Aluno: É! Outro estilo! Eu não vou falar, né? Porque eu não tô julgando não... mas não tem nada a ver...

(...) Aluno: E deixa só eu esclarecer, "estilo", pra mim, aquilo não é estilo, tá bom?

Aluna: Lógico que é estilo.

Aluno: Eu falei que aquilo é um estilo de viver de uma pessoa que não está bem da cabeça.

Aluna: Lógico que não, é estilo, ué! Se a pessoa acha que é bonito. Você acha que se ela achasse feio ela ia usar?

Aluno: Mas, não tá! Não tá bonito.

Aluna: Ué, é o estilo dela! É o jeito que ela pensa.

Aluno: Tá bom, tá bom! Quer ser parado toda hora pela polícia? Então tá bom.

Aluna: Nem todo mundo que usa short assim é parado pela polícia, depende do short...

Aluno: Mas normalmente quando a pessoa usa é.

Aluna: Não! Tipo se a pessoa tiver com um short preto, assim, com um símbolo da Nike, um tênis da Nike e uma blusa da Vans, ó...não vai ser parado pela polícia.

Professora: Então se for de marca...

Aluna: Não, só dei um exemplo, tipo, se a pessoa tá com um short todo estampado, um tênis da Mizuno e andando, sei lá, igual peba, lógico que ela vai ser parada, mas se ela andar com um short assim e souber se vestir ela não vai ser parada.

Aluno: Quer ser maloqueira? Seja maloqueira!

Professora: Mas aí a pessoa tem que andar de outra forma só porque ela vai ser parada pela polícia?

Aluno e aluna: Não

Aluno: Professora, a gente tá falando de 'desconfiômetro', entendeu?

Professora: Por que a polícia pararia alguém?

\footnotetext{
${ }^{5}$ Nome fictício.
} 


\section{ITHepapius REFLECTIONIS}

Revista Eletrônica de Graduação e Pós-Graduaçäo em Educaçāo

Aluna: Porque acha que é malandro.

Aluno: É! Tá certo! Tem que oprimir mesmo! Descer o cacete.

Professora: Você acha que o Fabrício tem que apanhar então?

Aluno e aluna: Não!!!

Aluno: Eu não falei isso não!

Aluna: Eu vou falar pra ele!

Aluno: É porque, geralmente, nego da minha idade, quer ser maloqueiro, quer ser ladrãozinho. Quer ser ladrãozinho? Tá bom, seja. Aí não gosta quando é parado pela polícia. Tendeu? Eu tô falando! Porque geralmente quem usa esse tipo de roupa é a pessoa que você já sabe, vive no crime, tráfico, essas coisas... entendeu?

\section{Aluna: Não, mas tipo, João, você sabe... tem muitos outros meninos lá na sala que usam short assim e você não fala que parece com maloqueiro.}

Quando o debate direcionou-se para estilos de roupa e como cada um se veste, ficou ainda mais nítido como ocorre a reprodução da construção da imagem do sujeito social, por meio de expressões e estereótipos, por exemplo, quando o aluno faz referência a palavra estilo e depois, por discordar de como a pessoa se veste, diz que aquilo não é estilo e enfatiza sua fala dizendo que quem se veste da forma citada não está bem da cabeça.

Enquanto um aluno menciona o estilo do seu colega de sala, julgando-o, a aluna faz ponderações a respeito do gosto pessoal de cada um, lógico que não, é estilo, ué! Se a pessoa acha que é bonito. Você acha que se ela achasse feio ela ia usar?, entretanto, os dois caminham na mesma vertente do estereótipo quando se fala a respeito das marcas de roupa, utilizando palavras de cunho pejorativo, como "maloqueiro, peba, ladrãozinho e malandro". Essa seleção lexical avaliativa revela que, para esses estudantes, a roupa é um fator determinante que justificaria o fato de pessoas serem paradas e agredidas pela polícia. A construção da imagem do jovem negro associado a um corpo marginalizado é reiterada a todo instante.

Outra questão relevante para se problematizar é o fato de André, que é citado como exemplo, ser o único negro retinto da sala, e ele é mencionado como a pessoa cujo estilo está associado ao tráfico de drogas. A reviravolta mais interessante da conversa é a percepção final da aluna, quando diz que existem outros meninos na sala, todos brancos, que ele não considera maloqueiros e se vestem da mesma forma que o André. Novamente os estereótipos de imagens social sendo reforçados em um aluno negro, estereótipos estes 


\section{MTIFAR REFLECTIONIS}

Revista Eletrônica de Graduaçāo e Pós-Graduaçäo em Educaçāo

que dizem respeito a forma de se vestir e está diretamente ligada a cor de pele. Como observa Bento (2011: 557),

a escola não é uma ilha. Embora saibamos que historicamente tem cumprido principalmente o papel de reprodutora de uma visão naturalizada das relações sociais, notamos que os debates que atravessam a sociedade brasileira também podem se sentir na sala de aula. Há um saudável incômodo de educadores/as, gestores/as das políticas públicas e do ativismo em trazer para o cotidiano escolar a reflexão dos direitos humanos em uma perspectiva ampla. Está em curso, portanto, a produção incessante de contra discursos, e a escola, de múltiplas formas, está inserida nessa disputa.

Considerando-se a observação da autora, entendemos de onde vêm as percepções dos/as estudantes, pois estes não vivem somente na escola ou somente fora desta, por fazerem parte do meio, reproduzem aquilo que assimilam em outros espaços e trazem para dentro da escola o discurso hegemônico normativo racista e patriarcal. Por isso, fazse essencial o papel do/a professor/a em sala de aula não apenas como um detentor do saber, como também um incentivador para a quebra de pensamentos, falas e atitudes cristalizadas.

\section{CONSIDERAÇÕES FINAIS}

Inicialmente, a perspectiva desse artigo era abordar gênero e raça, na perspectiva da mulher negra, entretanto, apesar de perceber durante a entrevista várias naturalizações em relação ao debate de gênero, o debate sobre a construção da imagem que se tem sobre um jovem de 13 anos, estudante, negro, nos chamou mais atenção. A leitura sobre a biografia de Elza Soares dando início ao projeto possibilitou que estas discussões ocorressem de forma natural, pois são os temas retratados em suas músicas. Mesmo que em fase inicial, é muito relevante o impacto das ações pedagógicas do projeto Mulheres Inspiradoras, pois por meio dele é possível debater machismo, racismo, LGBTfobia, por exemplo, em sala de aula. Nota-se que os/as estudantes pouco discutem tais assuntos, que são temas sociais, morais. Há crenças reproduzidas diariamente, e só podemos avançar e romper estruturas se falamos sobre elas e trazemos questionamentos aos/às estudantes. 


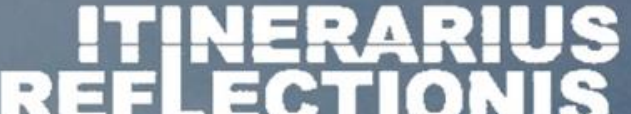 \\ REFLECTIONIS}

Revista Eletrônica de Graduaçāo e Pós-Graduaçāo em Educaçāo

Apesar de identificarmos falas reprodutores de preconceitos, percebemos um reconhecimento/uma reificação de que existem outras pessoas na sala que se "vestem como André", mas não são identificadas como "pebas". Nitidamente o fator raça é essencial para determinar como ambos enxergam o outro, constroem identificações de gênero-raça-classe. A fala aponta que a colaboradora reconhece, mesmo que não assim afirme, que o outro estudante está sendo racista em sua ponderação quando se trata de estilo. Como foi dito anteriormente, nossas visões de mundo não são construídas apenas dentro da escola. Mesmo com todos os debates, a influência da opinião dos responsáveis em casa e como a sociedade enxerga, classifica e separa os grupos em nichos constituem padrões discursivos e comportamentais, por isso é importante que a escola apresente outras visões e debates, contradiscursos, projetos pedagógicos inovadores, para não ser mais uma instituição que sustenta e reitera as formas de opressão social.

Dessa forma, nossa escolha pela pesquisa qualitativa transdisciplinar de paradigma crítico baseia-se no interesse pela descrição, interpretação e pela explanação de problemas sociais parcialmente discursivos, tendo em vista mudanças favoráveis ao bem comum. Buscamos identificar e problematizar padrões discursivos hegemônicos, como a nominalização/naturalização que podem sustentar relações assimétricas de poder. Somado a isso, buscamos identificar e estudar possíveis discursos contra-hegemônicos, a fim de mapear caminhos para a transformação social pautada na cooperação, na complementação, no cuidado, na valorização dos saberes e culturas locais, na igualdade política, econômica, social, de gênero, no bem comum, construindo a crítica latinoamericana situada dos usos da linguagem como instrumento de poder..

Fizemos um estudo qualitativo, por meio de pesquisa ação em uma escola localizada em Sobradinho-DF, para investigar aspectos sociodiscursivos (pedagógicos, identitários, interacionais, representacionais, relacionais) da implementação e dos resultados do Projeto Pedagógico "Mulheres Inspiradoras", desenvolvido em escolas públicas da SEDF com o objetivo de incentivar práticas de educação para a cidadania, para a equidade de gênero, combate ao racismo e para a transformação social.

Tivemos como principal resultado da pesquisa inicial a naturalização da imagem do corpo negro como um corpo marginalizado. Fizemos discussões em sala sobre machismo, feminismo, racismo e LGBTfobia, para problematizarmos o papel da 
educação linguística/literária na manutenção ou mudança de estruturas hegemônicas e crenças cristalizadas.

\section{REFERÊNCIAS}

ALBUQUERQUE, Gina Vieira Ponte de. Projeto Mulheres Inspiradoras: a pedagogia de projetos e o fortalecimento da identidade dos estudantes e das estudantes. Especialização em Letramentos e Práticas Interdisciplinares nos Anos Finais. Universidade de Brasília, 2015.

ALBUQUERQUE, Gina Vieira Ponte de; DIAS, Juliana de Freitas. Carta a uma professora: "não quero ser invisível, quero ser professora. Cadernos de Linguagem e Sociedade, 19 (3), 2018. http://periodicos.unb.br/index.php/les/article/view/18635.

BALLESTRIN, Luciana. América Latina e o giro decolonial. Rev. Bras. Ciênc. Política, Brasília, n. 11, p. 89-117, Aug. $2013 . \quad$ Disponível em: <http://www.scielo.br/scielo.php?script=sci_arttext\&pid=S010333522013000200004\&lng=en\&nrm=iso>. Acesso em 27 July 2016.

BENTO, Berenice. Na escola se aprende que a diferença faz a diferença. Rev. Estudos Feministas. [online]. 2011, vol.19, n.2, pp.549-559. ISSN 0104026X. http://dx.doi.org/10.1590/S0104-026X2011000200016. Acesso set. 2019.

BRASIL. Secretaria de Educação Fundamental. Parâmetros curriculares nacionais: introdução aos parâmetros curriculares nacionais/Secretaria de Educação Fundamental. Brasília: MEC/SEF, 1997.

CASTELLS, Manuel. O poder da identidade. Trad. Klauss B. Gerhardt. São Paulo: Paz e Terra, 2001.

CHOULIARAKI, Lilie \& FAIRCLOUGH, Norman. Discourse in late modernity: rethinking Critical Discourse Analysis. Edinburg: Edinburg University, 1999.

DUSSEL, Enrique. La filosofía europea no es universal. El espectador. Disponível em http://www.elespectador.com/noticias/actualidad/filosofiaeuropeanouniversalarticulo55 2386. 3 de abril de 2015. Acesso em 07 de abril de 2019.

FAIRCLOUGH, Norman. Analysing discourse. Textual analysis for social research. Londres; Routledge, 2003.

FREIRE, P. Pedagogia do oprimido. Rio de Janeiro: Paz e Terra, 2005[1970].

GROSFOGUEL, Ramon. Para descolonizar os estudos de economia política e os estudos pós-coloniais: transmodernidade, pensamento de fronteira e colonialidade global. Revista Crítica de Ciências Sociais, 2008, n. 80, p. 115-147.

JESUS, Carolina Maria de. Quarto de despejo: diário de uma favelada. São Paulo: Ática, 2007.

MOORE, Henrietta. Fantasias de poder e fantasias de identidade: gênero, raça e violência. Cadernos Pagu, n. 14, p. 13-44, jun. 2015. Disponível em: <http://periodicos.sbu.unicamp.br/ojs/index.php/cadpagu/article/view/8635341/3140>.

Acesso em: 29 jul. 2016. 


\section{MTIFAR REFLETIONIS}

Revista Eletrônica de Graduaçāo e Pós-Graduaçāo em Educaçāo

MOREY, Miguel. Introduccion. La cuestion del método. In: FOUCAULT, Michel. Tecnologias del yo y otros textos afines. Miguel Morey (Org.). Barcelona: Paidós, 1995, p. $9-44$.

QUIJANO, Aníbal. Colonialidad del poder, eurocentrismo y América Latina. In: La colonialidad del saber: eurocentrismo y ciencias sociales. Perspectivas Latinoamericanas. Edgardo Lander (Comp.) CLACSO, Consejo Latinoamericano de Ciencias Sociales, Buenos Aires: 2000. Disponible en: http://bibliotecavirtual.clacso.org.ar/ar/libros/lander/quijano.rtf. Acesso em 05 mar. 2016.

SOBRAL, Cristiane. Não vou mais lavar os pratos. Brasília: Athalaia, 2010.

SOBRAL, Cristiane. Só por hoje vou deixar meu cabelo em paz. Brasília: Teixeira, 2014.

SOUSA, V. A. \& CARVALHO, M. E. Por uma educação escolar não-sexista. João Pessoa: UFPB, 2003.

TORRES, Nelson Maldonado. Sobre la colonialidad del ser: contribuciones al desarrollo de un concepto. In: CASTRO-GÓMEZ, Santiago \& y GROSFOGUEL, Ramón (Comp.). El giro decolonial: reflexiones para una diversidad epistémica más allá del capitalismo global. Bogotá: Siglo del Hombre Editores; Universidad Central, Instituto de Estudios Sociales Contemporáneos y Pontifi cia Universidad Javeriana, Instituto Pensar, 2007, p. 127-167. 